\title{
Apremilast Normalizes Gene Expression of Inflammatory Mediators in Human Keratinocytes and Reduces Antigen-Induced Atopic Dermatitis in Mice
}

\author{
Peter H. Schafer ${ }^{1}$ (D - Mary Adams ${ }^{1} \cdot$ Gerald Horan $^{1} \cdot$ Francesca Truzzi $^{2} \cdot$ Alessandra Marconi $^{2} \cdot$ Carlo Pincelli $^{2}$
}

Published online: 9 October 2019

(c) The Author(s) 2019

\begin{abstract}
Background Apremilast, an oral phosphodiesterase (PDE) 4 inhibitor, has demonstrated efficacy in psoriasis, while its efficacy in atopic dermatitis (AD) was found to be modest. AD is a chronic inflammatory skin disease associated with activation of T helper (Th) 2 and Th17 immunity and a compromised epidermal barrier.

Objective The objectives of this study were to examine the expression of PDE4 isoforms in skin from healthy subjects and $\mathrm{AD}$ patients, and to determine the effects of apremilast on AD-related inflammatory markers in vitro and in murine models of AD.

Methods The expression of PDE4 isoforms (A, B, C, and D) in skin biopsies from healthy subjects and AD patients was evaluated using immunohistochemistry and digital image analysis. Using quantitative real-time reverse-transcriptase polymerase chain reaction, we evaluated the effects of apremilast on gene expression in adult human epidermal keratinocytes (HEKa) stimulated by Th2 and Th17 cytokines, and in two mouse models of antigen-induced AD.

Results Expression of PDE4 isoforms increased up to three-fold in the epidermis of AD patients versus healthy skin. In interleukin (IL)-4 and IL-17-stimulated HEKa cells, apremilast significantly changed the expression of ILs, including IL-12/ IL-23p40 and IL-31, and alarmins S100A7, S100A8, and S100A12. In mouse models of AD, apremilast significantly reduced ear swelling and monocyte chemoattractant protein-1 expression.

Conclusion PDE4 is overexpressed in AD skin compared with normal skin, and inflammatory gene expression by human keratinocytes and mouse dermatitis can be modulated by apremilast.
\end{abstract}

Peter H. Schafer

pschafer@celgene.com

Mary Adams

madams@celgene.com

Gerald Horan

ghoran@celgene.com

Francesca Truzzi

truzzi.francesca@gmail.com

Alessandra Marconi

alessandra.marconi@unimore.it

Carlo Pincelli

carlo.pincelli@unimore.it

1 Sol J. Barer Laboratories, Department of Translational Development, Celgene Corporation, 181 Passaic Avenue, Summit, NJ 07901, USA

2 Laboratory of Cutaneous Biology, Department of Surgical, Medical, Dental and Morphological Sciences, University of Modena and Reggio Emilia, Modena, Italy

\section{Key Points}

In the atopic dermatitis (AD) epidermis, phosphodiesterase (PDE) 4 isoform expression is increased up to threefold compared with healthy skin.

PDE4 inhibition with apremilast significantly changed messenger RNA expression of several interleukins (ILs), alarmins, and small proline-rich protein, in IL-4- and IL17-stimulated adult human epidermal keratinocyte cells.

In mouse models of $\mathrm{AD}$, apremilast significantly reduced ear swelling and monocyte chemoattractant protein-1 protein expression.

Results highlight the potential direct effects and limitations of PDE4 inhibition on keratinocyte responses in AD. 


\section{Introduction}

Atopic dermatitis (AD), also known as atopic eczema, is an inflammatory, chronically relapsing skin disease [1] that is often associated with other atopic diseases [2-4]. AD typically begins in early childhood, generally before 2 years of age, and often persists into adulthood. Epidermal barrier defects (e.g., filaggrin [FLG] mutations) and an altered immune response, both innate and adaptive, are core pathophysiological features in patients with AD [1]. The rapid innate immune response is mediated by several receptors that are expressed in keratinocytes and antigenpresenting cells and are thought to prevent microbial replication [5]. Stimulation of these immune receptors by microbes or through tissue injury leads to the release of antimicrobial peptides, cytokines, and chemokines that enhance the strength of tight junctions to limit penetration of allergens and microbes. Studies have demonstrated that patients with AD have reduced production of keratinocyte-derived antimicrobial peptides, which are needed to control infection by Staphylococcus aureus and viruses [5]. Therefore, these patients may be predisposed to microbial colonization and chronic skin inflammation.

Allergic inflammation also significantly reduces the antimicrobial peptide response in these patients, which may increase the risk of skin infection [5, 6]. Moreover, in the epidermis, Langerhans cells are thought to play a critical role in the initiation of allergic inflammation, which ultimately results in the activation of specific $\mathrm{T}$ cells with expression of T helper (Th) 2 cytokines (interleukin [IL]-4, IL-13, and IL-5) [7, 8], especially in the acute lesions. In contrast, Th1 cytokines play a key role in chronic lesions [2]. Evidence from recent research also supports a role for IL-22 and a modest role for IL-17, including IL-17-related genes (i.e., CXCL1, CXCL2, P13, IL-23p19/IL-23A, and S100A12), in the disease progression of AD [9-11].

Cyclic adenosine monophosphate (cAMP) is a pivotal secondary messenger that results in the inhibition of the synthesis and release of pro-inflammatory mediators and cytokines [12]. cAMP and cyclic guanosine monophosphate are degraded through the activity of the large superfamily of phosphodiesterase (PDE) isoenzymes (1-11) [13]. Within this group, enzymes of the four-gene PDE4 family play a key role in degrading cAMP in inflammatory cells as well as in endothelial cells, smooth muscle cells, and keratinocytes $[14,15]$. More than 20 splice variants are encoded by the $P D E 4 A, P D E 4 B, P D E 4 C$, and PDE4D genes due to differential messenger RNA (mRNA) splicing [14, 16]. PDE4 isoforms display a differential expression pattern in human testis, skeletal muscle, lung, and brain [17-19]. The overexpression of PDE4 isoforms in the dermis and blood of psoriasis patients has previously been reported [20]. However, the expression patterns of PDE4 isoforms have not been described in the epidermis of patients with AD. An earlier study has demonstrated that PDE activity was increased in mononuclear leukocytes from patients with AD [21]. Inhibitors of PDE4 elevate intracellular cAMP levels, which then inhibit a broad range of pro-inflammatory mediators, with activities in vitro and in preclinical models of asthma, lung neutrophilia, arthritis, inflammatory bowel disease, multiple sclerosis, osteoporosis, and other disease states [22-27].

Apremilast is a novel, orally administered, small-molecule PDE4 inhibitor approved for treatment of adult patients with psoriatic arthritis, patients with moderate to severe plaque psoriasis, and patients with oral ulcers associated with Behçet's syndrome [20, 28]. By inhibiting PDE4, apremilast elevates intracellular cAMP levels and thus down-regulates the inflammatory response by modulating expression of a network of pro-inflammatory mediators such as tumor necrosis factor- $\alpha, \mathrm{IL}-23$, and IL-17 [25, 29, 30]. Apremilast can also increase anti-inflammatory mediators such as IL-10 and the IL-1 receptor antagonist in psoriasis and psoriatic arthritis patients [29, 31].

There are multiple models of $\mathrm{AD}$ in the mouse, using various antigens such as fluorescein isothiocyanate (FITC) [32] and dinitrochlorobenzene (DNCB) [33]. These models rely on a sensitization period wherein the antigen is applied directly to the skin of the abdomen or flank to allow dendritic cells to process and present the antigen to reactive $\mathrm{T}$ cells, which clonally expand and produce Th2 and Th17 cytokines and chemokines. This sensitization period is followed by an antigenic challenge period during which the same antigen is then applied to the ears on 1 or more days. The immune response can be gauged by measuring the ear thickness using calipers, and by isolating proteins from ear tissue homogenate to measure cytokine and chemokine levels. For example, the FITC model is characterized by elevated expression of IL-1 $\beta$, IL-4, IL-5, IL-6, IL-13, IL-17, eotaxin, monocyte chemoattractant protein (MCP)-1/chemokine (C-C motif) ligand (CCL)-2, macrophage inflammatory protein (MIP)-1 $\alpha /$ CCL4, RANTES (Regulated on Activation, Normal T Cell Expressed and Secreted), and thymus and activation-regulated chemokine (TARC) in the ear tissue [32]. AD therapeutics have been successfully tested in these models. For example, the mouse DNCB model has been used to demonstrate efficacy of systemically administered ciclosporin (cyclosporine A) [34]. DNCB has also been used as an antigen applied to the skin of healthy human volunteers to demonstrate the clinical efficacy of topical corticosteroids clobetasol propionate $0.05 \%$ versus betamethasone valerate $0.1 \%$ [35].

The goals of these studies were to (a) assess the expression of PDE4 isoforms in the epidermis of healthy subjects and patients with $\mathrm{AD}$; (b) determine the direct effects of PDE4 inhibition on Th2 (IL-4)- and Th17 (IL-17)-induced 
gene expression in primary adult human epidermal keratinocytes (HEKa); and (c) assess the effects of apremilast in two mouse models of AD using two antigens, FITC [32] and DNCB [33].

\section{Materials and Methods}

\subsection{Immunohistochemistry}

Immunohistochemistry was used to evaluate the expression of PDE4 isoforms in human skin. Archived skin biopsies (4\% buffered, formalin fixed and paraffin embedded) from three healthy subjects and five AD patients were used for the analysis. Tissue sections $(4 \mu \mathrm{m})$ were cut and deparaffinized in xylene and rehydrated in graded alcohol. The slides were first boiled in citrate buffer, $\mathrm{pH} 6$, for $20 \mathrm{~min}$ in a standard pressure cooker. For PDE4A and CD1a expression, slides were incubated with hydrogen peroxidase block for $5 \mathrm{~min}$ at room temperature, as indicated by the datasheet. All slides were incubated with ultra $\mathrm{V}$ block for $5 \mathrm{~min}$ at room temperature to block non-specific background staining. After that, expression of PDE4A, PDE4B, PDE4C, and PDE4D were examined immunohistochemically by incubating the samples for $1 \mathrm{~h}$ at room temperature with the following antibodies: PDE4A antibody (1:100; ProteinTech Group Inc., Chicago, IL, USA), PDE4B (1:100; Santa Cruz Biotechnology, Inc., Santa Cruz, CA, USA), PDE4C (1:100; Santa Cruz Biotechnology, Inc.), and PDE4D (1:100; Santa Cruz Biotechnology, Inc.) and CD1a (ready to use, Roche Diagnostics, Ventana, Tucson, AZ, USA). After three 5-min washes in phosphate-buffered saline (PBS), slides were incubated with secondary antibody for $45 \mathrm{~min}$ at room temperature followed by incubation with naphtol phosphate substrate for $10 \mathrm{~min}$ for PDE4B, PDE4C, and PDE4D detection, as suggested by the datasheet (Lab Vision Corporation, Fremont, CA, USA). For both PDE4A and CD1a expression, slides were incubated with streptavidin peroxidase for $5 \mathrm{~min}$ at room temperature. After four 5-min washes in PBS, slides were incubated with ready-to-use aminoethyl carbazole (AEC) Single Solution for $10 \mathrm{~min}$ as suggested by the datasheet (Lab Vision Corporation). Negative controls were obtained by omitting the primary antibody. The expression intensity was quantitatively determined using ImageJ software (Wayne Rasband, National Institute of Mental Health, Bethesda, MD, USA). Total positive pixels were compared with healthy skin total positive pixels, which were indicated as 1 .

\subsection{Human Primary Adult Keratinocyte Cultures}

Primary HEKa (ScienCell Research Laboratories, Carlsbad, CA, USA) were thawed, cultured in a T75 flask containing
$\mathrm{KGM}^{\mathrm{TM}}$ Gold medium plus supplements for human cells (15 mL; Lonza, Walkersville, MD, USA) and incubated in $5 \% \mathrm{CO}_{2}$ at $37{ }^{\circ} \mathrm{C}$. The cells were cultured for $4-6$ days ( $90 \%$ confluence) with media replenishment after the first $24 \mathrm{~h}$. Upon achieving confluence, the media was removed; the cell monolayer was rinsed with PBS and trypsinized $(1 \mathrm{~mL}$ of $0.05 \%$ trypsin). Fetal bovine serum $(10 \mathrm{~mL})$ was added after 5-10 min and the cells were centrifuged (Eppendorf Centrifuge 5810R) at $1200 \mathrm{rpm}$ (Rotor A-4-81) for $5 \mathrm{~min}$ (Eppendorf AG, Hamburg, Germany). The cell pellet was rinsed in PBS, then re-suspended in fresh medium. Cells were then plated in six well plates and incubated for 4-6 h in $5 \% \mathrm{CO}_{2}$ at $37{ }^{\circ} \mathrm{C}$ to allow attachment and grown until they were $80-90 \%$ confluent. Cells were serum-starved overnight.

Apremilast $(1.5 \mu \mathrm{M})$ or dimethyl sulfoxide (DMSO) was added and plates were incubated in $5 \% \mathrm{CO}_{2}$ at $37{ }^{\circ} \mathrm{C}$ for $1 \mathrm{~h}$. IL-4 $(10 \mu \mathrm{g})$ was suspended in $100 \mu \mathrm{L}$ of PBS containing $0.05 \%$ bovine serum albumin for a final concentration of $1 \mathrm{mg} / \mathrm{mL}$. IL-17a (25 $\mu \mathrm{g})$ was re-suspended in $250 \mu \mathrm{L}$ of PBS containing $0.05 \%$ bovine serum albumin for a final concentration of $1 \mathrm{mg} / \mathrm{mL}$. A $10 \mu \mathrm{g} / \mathrm{mL}$ stock was made by diluting $10 \mu \mathrm{L}$ of IL-4 or IL-17a into $990 \mu \mathrm{L}$ media. For a final concentration of $10 \mathrm{ng} / \mathrm{mL}, 5 \mu \mathrm{L}$ of diluted IL-4 was added to the cells. For $50 \mathrm{ng} / \mathrm{mL}$ IL-17a final concentration, $25 \mu \mathrm{L}$ of diluted stock was added to the cells. Plates were incubated for $24 \mathrm{~h}$ in $5 \% \mathrm{CO}_{2}$ at $37{ }^{\circ} \mathrm{C}$. Cells were washed with cold PBS and then $350 \mu \mathrm{L}$ RLT buffer (Qiagen, Valencia, CA, USA; catalog \#79216) was added to each sample. A concentration of $1.5 \mu \mathrm{M}$ of apremilast was selected for the HEKa experiments because it is equivalent to the apremilast $30 \mathrm{mg}$ twice daily clinical maximum concentration $\left(C_{\max }\right)$ of $670 \mathrm{ng} / \mathrm{mL}$, based on a molecular weight of $460.5[28,36]$.

\subsection{Quantitative Real-Time Reverse-Transcriptase Polymerase Chain Reaction}

Expression of the following AD-related genes was measured by quantitative real-time reverse-transcriptase polymerase chain reaction (RT-PCR): $I L-12 B, I L-23 A$, and $I L-19$; CCL5, CCL17, and CCL18; pruritus mediators IL-31 and IL-33; terminal differentiation markers FLG, loricrin, periplakin, and small proline-rich protein 1A (SPRR1A); keratin 16; alarmins S100A7, S100A8, and S100A12; and defensin DEFB4B. Lysates were harvested for total RNA preparation with a QIAcube RNA extraction instrument (Qiagen, Valencia, CA, USA) using QIAGEN RNeasy ${ }^{\circledR}$ mini spin-column kits (catalog \#74104). Purified RNA was reverse transcribed into complementary DNA with a thermal cycler (Life Technologies, Grand Island, NY, USA) using the reverse-transcriptase kit (Life Technologies). The gene expression assay was carried out using the ViiA ${ }^{\text {TM }} 7$ RT-PCR system (Life Technologies) in triplicate. A glyceraldehyde 3-phosphate 
dehydrogenase gene expression assay control was run for each sample and used as a normalization control.

Data are expressed as relative gene expression or relative quantification, where fold increase was defined as 2 -ddCt (2-delta delta cycle threshold values). Relative quantification values were normalized to stimulation controls (DMSO). Significance versus the DMSO control was calculated using multiple two-tailed Student's $t$ tests using GraphPad Prism 6 (GraphPad Software, Inc., La Jolla, CA, USA).

\subsection{Mouse Models of Atopic Dermatitis}

$\mathrm{Balb} / \mathrm{c}$ mice were sensitized to antigens by applying either DNCB $(n=40)$ or FITC $(n=40)$ to the flanks on days 0 and 5. From day 6 through day 12, mice received orally either vehicle (carboxy-methylcellulose and Tween ${ }^{\circledR} 80$ [Sigma-Aldrich, St Louis, MO, USA] in sterile water; $n=10$ ), apremilast $2.5 \mathrm{mg} / \mathrm{kg}$ twice daily $(n=10)$, apremilast $5 \mathrm{mg} / \mathrm{kg}$ twice daily $(n=10)$, or dexamethasone $1 \mathrm{mg} / \mathrm{kg}$ once daily $(n=10)$. The apremilast doses of 2.5 and $5 \mathrm{mg} / \mathrm{kg}$ twice daily were selected to represent doses that are $50 \%$ and $100 \%$ of the no observed adverse effect level of $10 \mathrm{mg} / \mathrm{kg} / \mathrm{day}$, as determined in a 6-month mouse toxicology study [37]. Apremilast was dissolved in vehicle and administered in a volume of $5 \mathrm{~mL} / \mathrm{kg}$. Dexamethasone was dissolved in ethanol and PBS and administered in a volume of $10 \mathrm{~mL} / \mathrm{kg}$. On days 10,11 , and 12 , antigens were applied to both ears. Thickness was measured on both ears by a digital caliper on days -1 (baseline), 5 (prior to sensitization), 10, 11, 12 , and 13 when the animals were euthanized and the left ear was homogenized and the protein levels of IL-22, IL-4, IL-10, IL-13, IL-17A, MCP-1, RANTES, IL-12p40, and IL-23 were measured using the Lumine ${ }^{\circledR}$ Assay.

Experiments were performed by MD Biosciences (St. Paul, MN, USA) following approval of an application submitted to the Committee for Ethical Conduct in the Care and Use of Laboratory Animals that stated the study complied with the rules and regulations set forth by the committee. Data were expressed as mean \pm standard error of the mean (SEM) and were analyzed with one-way analysis of variance followed by Tukey's test (GraphPad). $P \leq 0.05$ represented a significant difference.

\section{Results}

\subsection{All Phosphodiesterase 4 Isoforms are Up-Regulated in the Epidermis from Patients with Atopic Dermatitis}

In skin biopsies from healthy subjects, PDE4A was expressed in both the epidermal and dermal compartments. In the epidermis, expression in keratinocytes was strongest at the cytoplasmic level in the high spinous and granular layers. Scattered dermal cells were also strongly positive for PDE4A (Fig. 1). PDE4A staining was increased in AD compared with healthy skin. PDE4A was markedly expressed at the cytoplasmic level in all epidermal suprabasal layers, particularly in the highest spinous layers.

In skin from healthy subjects, PDE4B was only expressed in dermal cells, with no expression in the epidermis. In skin biopsies from patients with $\mathrm{AD}, \mathrm{PDE} 4 \mathrm{~B}$ staining was mostly negative in the epidermal compartment, except for intra-epidermal dendritic cells where PDE4B was markedly expressed at the cytoplasmic level. In consecutive sections, similar cell types were also positive for CD1a staining, a marker for Langerhans cells, strongly suggesting that these dendritic cells express PDE4B (Fig. 1). PDE4C staining was negative in all layers of the epidermal compartment in skin biopsies from healthy subjects. In skin biopsies from patients with $\mathrm{AD}, \mathrm{PDE} 4 \mathrm{C}$ staining was observed in both the epidermis and dermis, and weakly expressed in keratinocytes of the spinous layer at the membrane level. PDE4C was also expressed in epidermal dendritic cells, similarly to cell types positive for CD1a and PDE4B in consecutive sections, suggesting that Langerhans cells may also express PDE4C (Fig. 1).

In skin from healthy subjects, PDE4D staining was negative in all epidermal layers from abdominal skin (not shown). However, in biopsies obtained from foreskin, PDE4D expression was weakly positive in basal keratinocytes at the cytoplasmic level (Fig. 1). In skin biopsies from patients with $\mathrm{AD}$, PDE4D staining was higher in abdominal skin than in foreskin. Basal and suprabasal keratinocytes were PDE4D positive at the cytoplasmic level.

Relative to healthy subjects, the expression intensity of all PDE4 isoforms was significantly increased in the epidermis by 2.49- to 3.10-fold in patients with AD. Additionally, PDE4D was also significantly increased in the dermis by 2.79-fold in patients with AD (Fig. 1).

\subsection{Apremilast Normalizes Gene Expression of Inflammatory Mediators in Adult Human Epidermal Keratinocytes}

IL-4 stimulation significantly $(P<0.05)$ increased gene expression of $I L-19$ (25-fold), $I L$-33 (2.5-fold), $I L-31$ (2.3fold), CCL5 (2.3-fold), CCL18 (two-fold), IL-12B (1.7-fold), and KRT16 (1.2-fold) in human adult epithelial keratinocytes. Conversely, IL-4 stimulation significantly $(P<0.05)$ decreased gene expression of $D E F B 4 B$ (two-fold), IVL (2.4fold), and $C C L 17$ (3.4-fold). In IL-4-stimulated keratinocytes, apremilast significantly inhibited $I L-12 / I L-23 p 40$, IL-31, CCL5, FLG, SPRR1, S100A7, S100A8, and S100A12 gene expression, and attenuated the inhibitory effect of IL-4 on $C C L 17$ gene expression (Fig. 2a).

IL-17 significantly $(P<0.05)$ increased gene expression of DEFB4 (200-fold), IL-19 (23-fold), S100A12 (13-fold), 
a
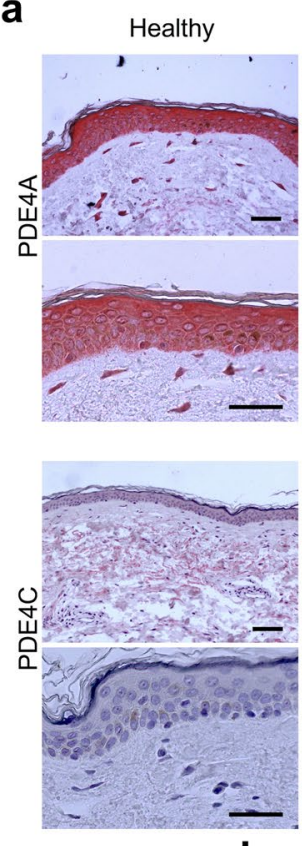

b
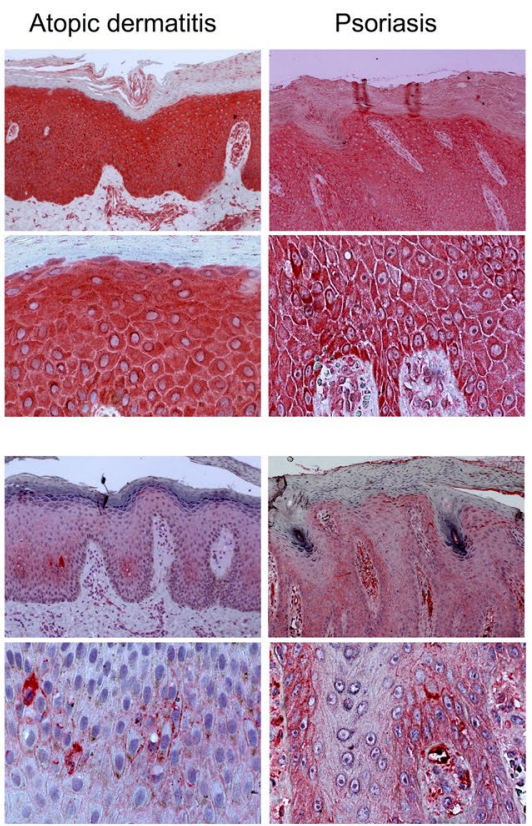

\begin{tabular}{|c|c|c|c|}
\hline & & Atopic Dermatitis & Psoriasis \\
\hline \multirow{2}{*}{ PDE4A } & Epidermis & $2.63 \pm 0.28 *$ & $1.86 \pm 0.34$ * \\
\hline & Dermis & $1.21 \pm 0.16$ & $1.24 \pm 0.12$ \\
\hline \multirow{2}{*}{ PDE4B } & Epidermis & $2.69 \pm 0.31 *$ & $1.37 \pm 0.19$ \\
\hline & Dermis & $1.36 \pm 0.19$ & $1.67 \pm 0.20 *$ \\
\hline \multirow{2}{*}{ PDE4C } & Epidermis & $3.10 \pm 0.33 *$ & $1.44 \pm 0.12$ \\
\hline & Dermis & $1.60 \pm 0.19$ & $1.83 \pm 0.13$ * \\
\hline \multirow{2}{*}{ PDE4D } & Epidermis & $2.49 \pm 0.25 *$ & $2.29 \pm 0,32$ * \\
\hline & dermis & $2.78 \pm 0.21 *$ & $2.42 \pm 0,24 *$ \\
\hline
\end{tabular}

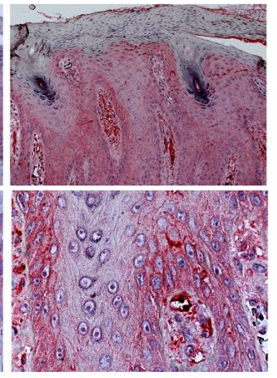

Healthy
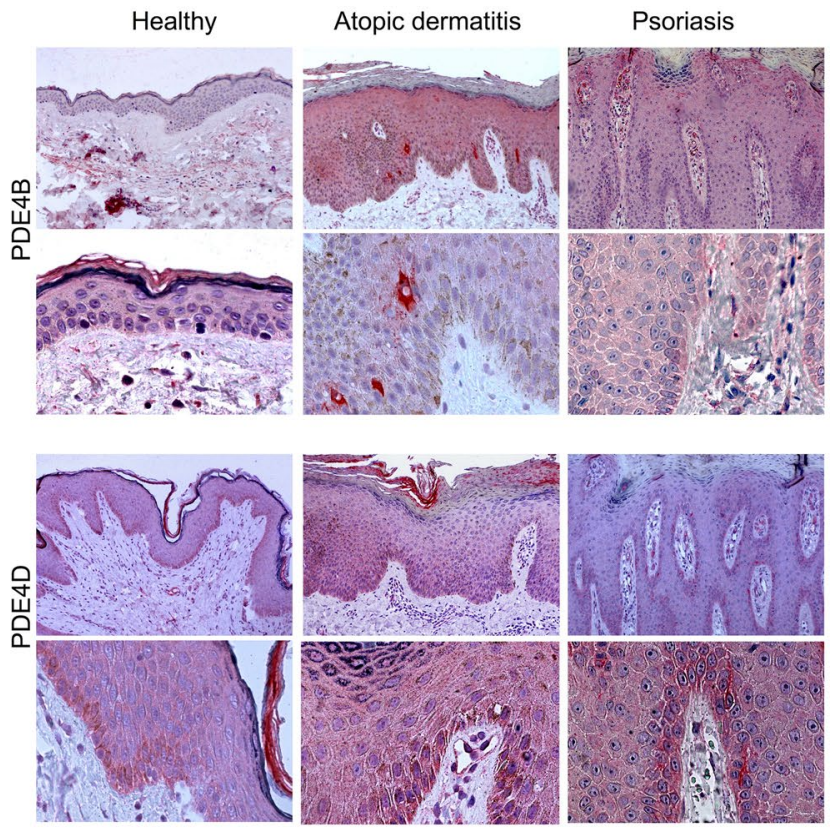

C

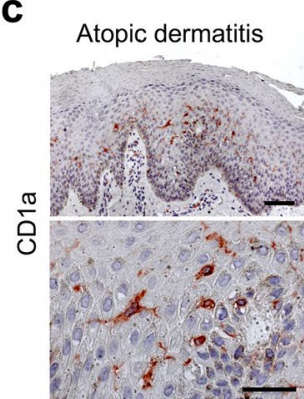

Fig. 1 Expression and quantitative assessment of phosphodiesterase (PDE) 4 isoform protein levels in epidermal skin from patients with atopic dermatitis (AD). PDE4A, PDE4B, PDE4C, PDE4D, and CD1a in epidermal and dermal layers from healthy controls and patients with $\mathrm{AD}$ were detected with immunohistochemistry. Total positive

S100A7 (seven-fold), S100A8 (five-fold), IL-23a (five-fold), CCL17 (2.7-fold), CCL18 (1.9-fold), $I L$-33 (1.7-fold), $I L$ 12/IL-23p40 (1.4-fold), IL-31 (1.3-fold), and SPRRIA (1.1-fold). IL-17 significantly $(P<0.05)$ decreased gene expression of loricrin (1.42-fold) and FLG (two-fold). In IL-17-stimulated keratinocytes, apremilast significantly inhibited $I L-12 / I L-23 p 40, I L-19, I L-31, I L-33$, loricrin, SPRR1, S100A7, S100A8, and S100A12 gene expression, and increased $C C L 18$ gene expression (Fig. 2b).

\subsection{Apremilast Reduces Ear Swelling in Mouse Models of Dermatitis}

Apremilast (2.5 and $5 \mathrm{mg} / \mathrm{kg}$ twice daily) significantly reduced ear swelling in two models of dermatitis (Fig. 3). In the FITC model, ear thickness significantly pixels in the epidermis and dermis from patients with AD were compared to total positive pixels from healthy subjects. The measured fold increase in PDE4 isoform expression in patients with AD relative to healthy controls is given. ${ }^{*} P<0.05$, paired Student's $t$ test

$(P<0.05)$ increased from $0.19 \pm 0.00 \mathrm{~mm}$ (baseline) to $0.50 \pm 0.02 \mathrm{~mm}$ (day 13) in vehicle-treated mice. Dexamethasone $1 \mathrm{mg} / \mathrm{kg}$ significantly reduced ear thickness to $0.34 \pm 0.01 \mathrm{~mm}$ on days $11-13$ compared with vehicletreated mice $(P<0.05)$. Similarly, apremilast 2.5 and $5 \mathrm{mg} /$ $\mathrm{kg}$ significantly reduced ear thickness to $0.40 \pm 0.01 \mathrm{~mm}$ and $0.41 \pm 0.01 \mathrm{~mm}$, respectively, on days 11-13 compared with vehicle-treated mice $(P<0.05)$.

In the DNCB model, ear thickness significantly $(P<0.05)$ increased from $0.21 \pm 0.00 \mathrm{~mm}$ (baseline) to $0.43 \pm 0.01 \mathrm{~mm}$ (day 13) in vehicle-treated mice. Dexamethasone significantly $(P<0.05)$ decreased ear swelling to $0.29 \pm 0.00 \mathrm{~mm}$ on days $11-13$ compared with vehicle-treated mice. Apremilast 2.5 and $5 \mathrm{mg} / \mathrm{kg}$ also significantly reduced ear thickness to $0.37 \pm 0.01 \mathrm{~mm}$ and $0.39 \pm 0.01 \mathrm{~mm}$ on days 11 and 13 , respectively, 

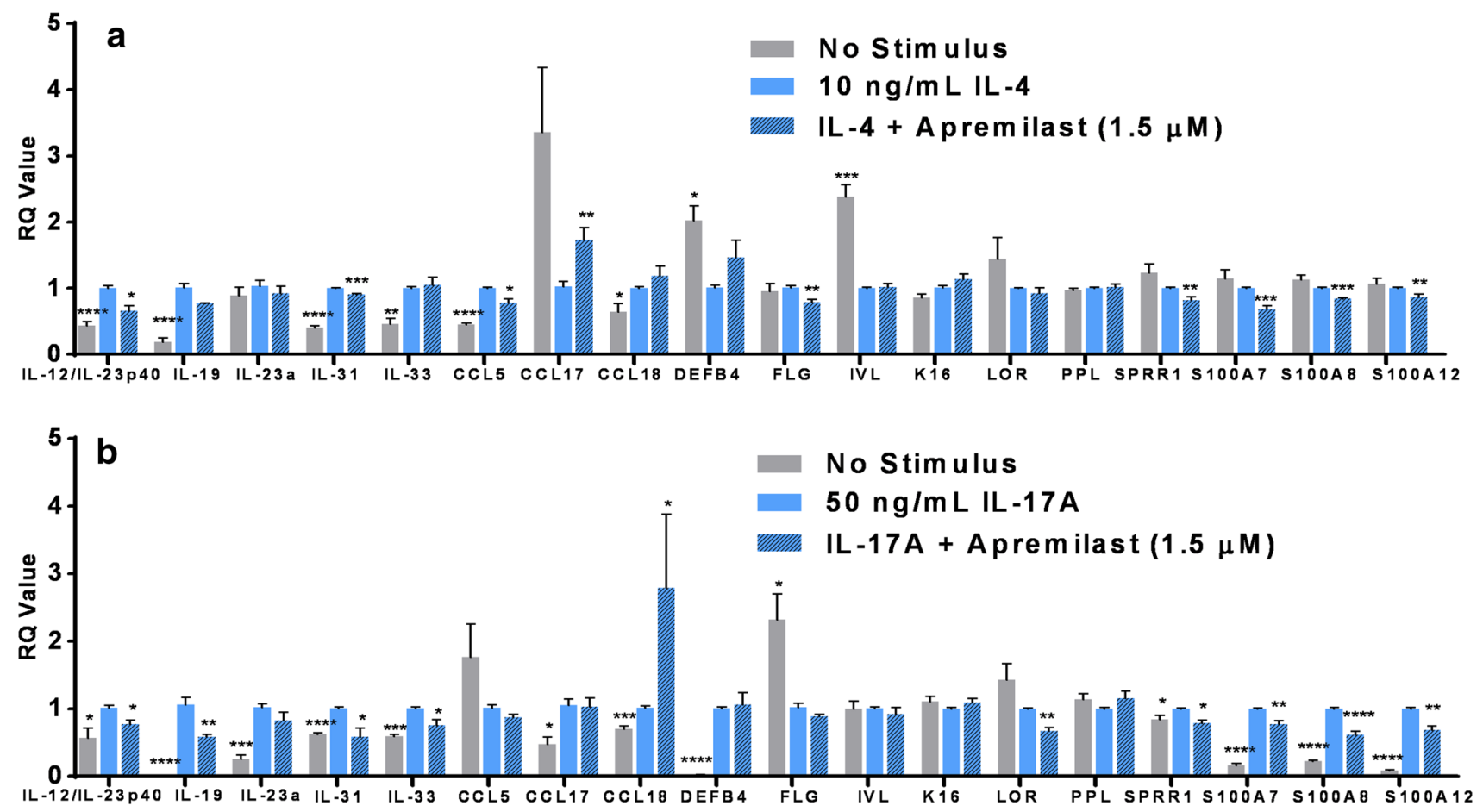

Fig. 2 Effect of apremilast on interleukin (IL)-4- and IL-17-stimulated adult human epidermal keratinocytes (HEKa). a IL-4-stimulated HEKa; b IL-17A-stimulated HEKa. Data are expressed as the mean \pm standard error of the mean, relative to IL-4 or IL-17 control, from three normal human keratinocyte cells, each tested in triplicate. $R Q$ relative quantification, $* P<0.05, * * P<0.01$, *** $P<0.001$, $* * * * P<0.0001$ vs. IL-4 or IL-17 control by paired Student's $t$ tests

there were subtle differences between the two diseases, with the AD dermis expressing slightly higher levels of PDE4D and the psoriatic dermis expressing higher levels of PDE4A [20]. In the current study, the AD epidermis displayed a PDE4B and PDE4C expression pattern that resembled that of CD1a, a marker of Langerhans cells, suggesting that these dendritic cells express both PDE4B and PDE4C. In contrast, AD keratinocytes expressed PDE4A and PDE4D. The PDE4A expression pattern was predominantly epidermal in AD skin, while the PDE4D expression pattern was both epidermal and dermal. In primary human epidermal keratinocytes stimulated with either IL-4 or IL-17, PDE4 inhibition with apremilast significantly reduced mRNA expression of IL-12/IL-23p40, the itch cytokine IL-31, SPRR1, and the alarmins S100A7, S100A8, and S100A12. Finally, in both mouse models of dermatitis, apremilast significantly reduced ear swelling and MCP-1 protein expression.

Langerhans cells play a critical role in $\mathrm{AD}$, in both mice and humans. For instance, Langerhans cells penetrate the tight junctions that separate the stratum corneum from the stratum granulosum in human $\mathrm{AD}$ skin $[38,39]$. A recent preclinical study [40] indicated that mice deficient in myeloid differentiation primary response gene 88 (MYD88) had 
Fig. 3 Effects of apremilast in the dinitrochlorobenzene (DNCB) (a) and fluorescein isothiocyanate (FITC) (b) mouse models of dermatitis. Data are expressed as the mean \pm standard error of the mean. Sensitization to either DNCB or FITC (applied to the flanks) occurred on days 0 and 5 . All animals received the DNCB or FITC antigen, including vehicle. Both ears were challenged with either DNCB or FITC on days 10, 11, and 12. Ear thickness was measured on each day. $* P<0.05$ vs. vehicle using one-way analysis of variance followed by Tukey's test for pairwise comparisons

\section{DNCB}

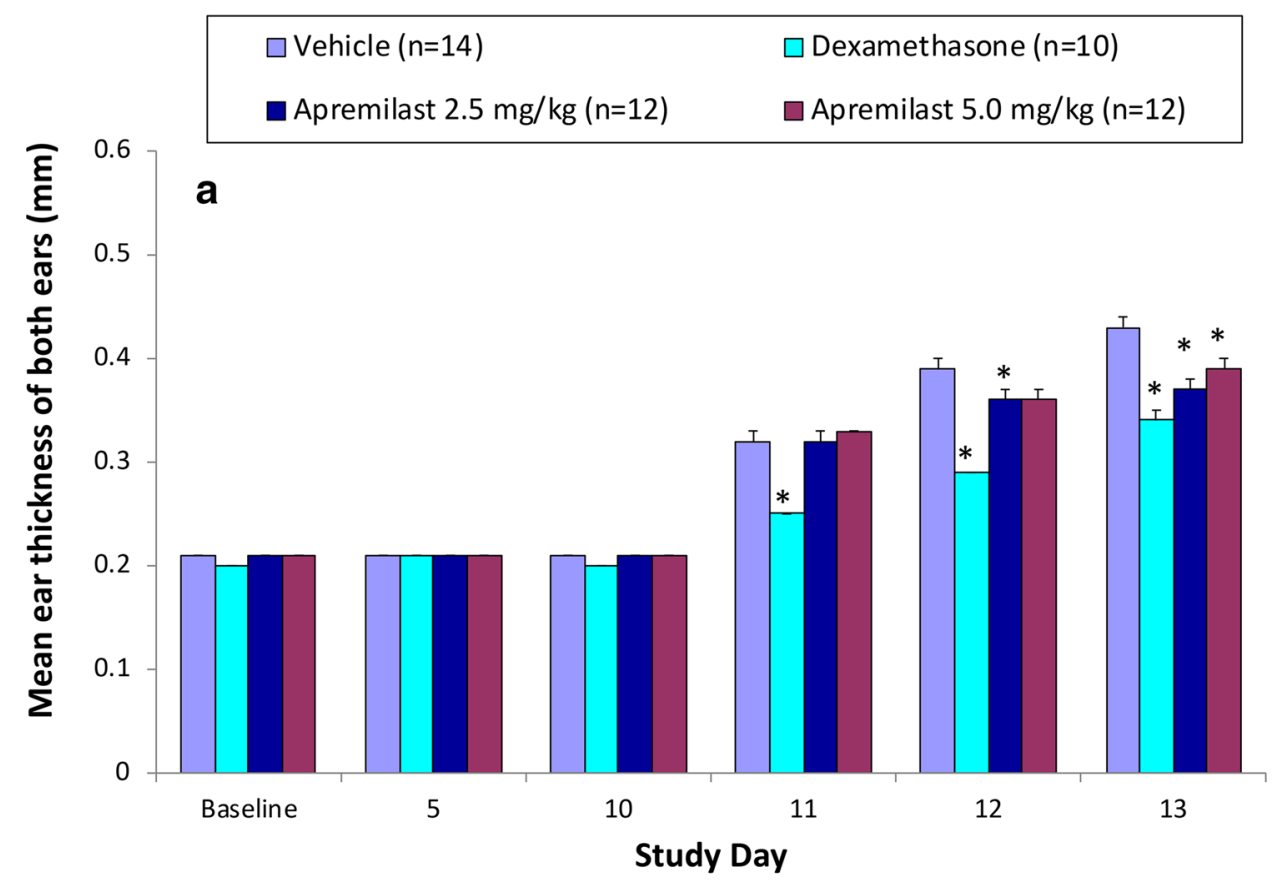

FITC

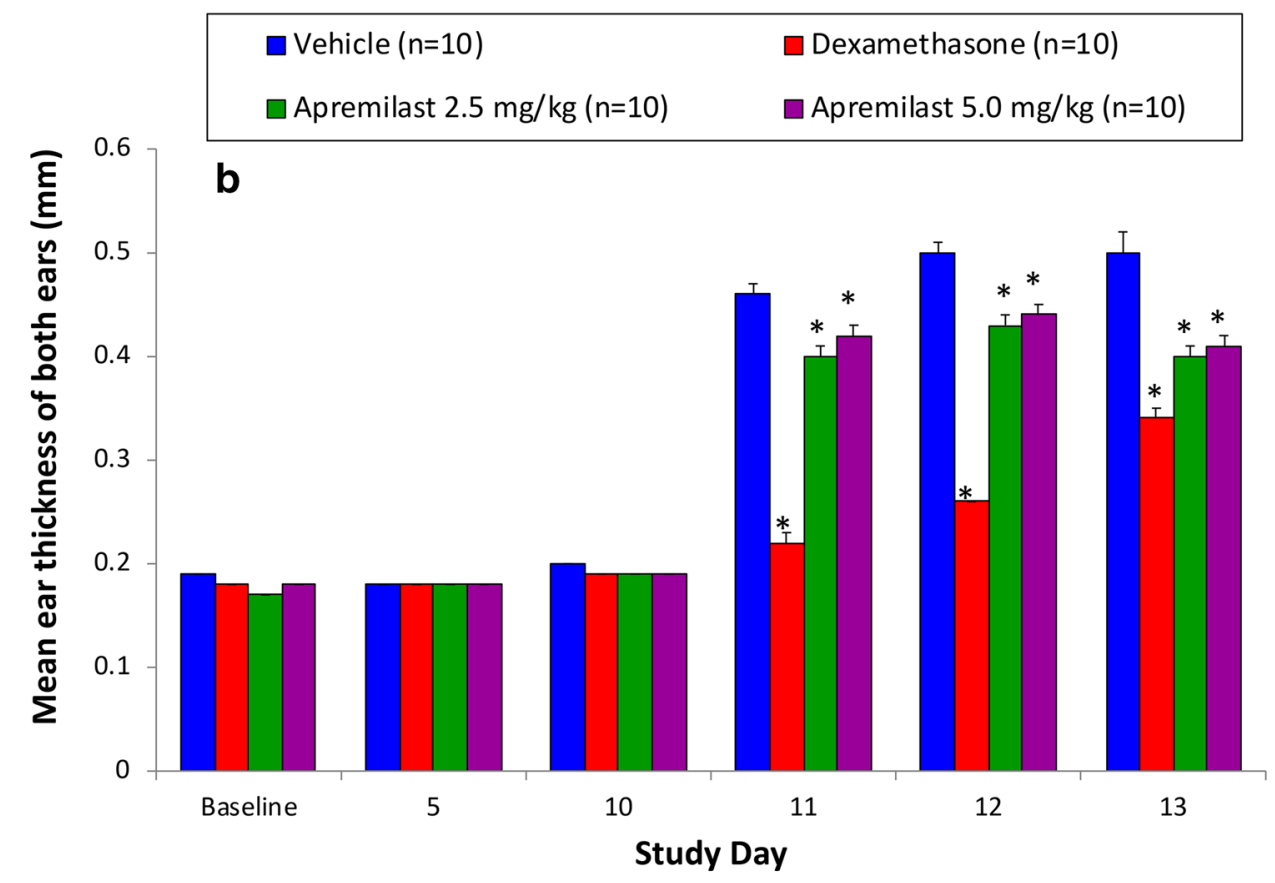

reduced epidermal thickening and diminished accumulation of macrophages within the inflamed skin. In addition, these mice had impaired emigration of Langerhans cells out of the epidermis. A separate study demonstrated that patients with AD had significantly higher production of both CCL17 and CCL22 monocyte-derived Langerhans cells than healthy controls [39]. These recent published data are consistent with our results obtained in mouse models of dermatitis.

Inhibition of PDE4 elevates intracellular cAMP levels, which then inhibit a broad range of pro-inflammatory mediators with activities in vitro and in preclinical models of asthma, lung neutrophilia, arthritis, inflammatory bowel 

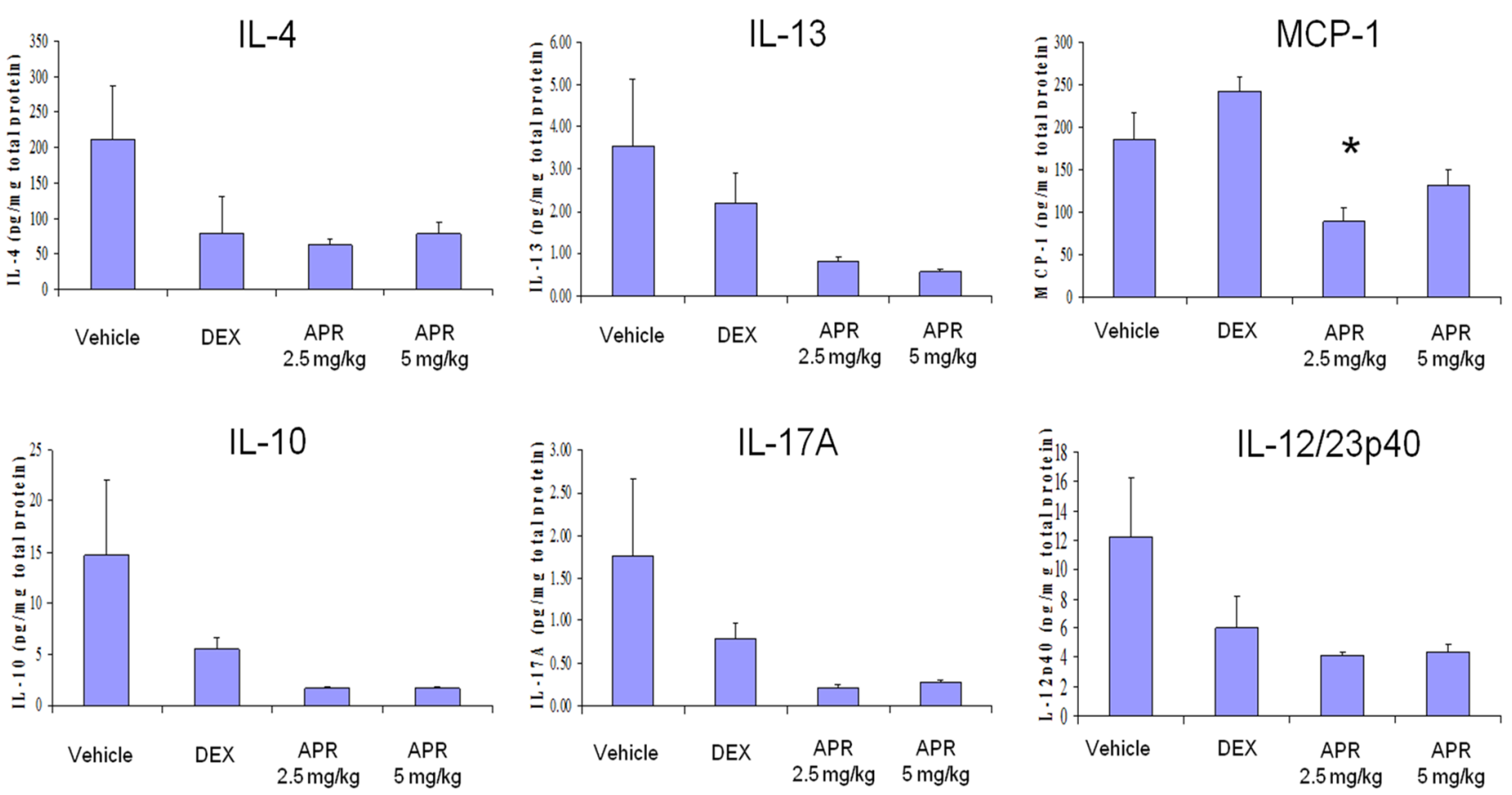

Fig. 4 Effects of apremilast (APR) on cytokine protein levels in the dinitrochlorobenzene (DNCB) mouse model of atopic dermatitis. Protein levels of interleukin (IL)-4, IL-10, IL-13, IL-17A, and IL$12 / 23$ p 40 were measured in the inflamed ear subsequent to DNCB

disease, multiple sclerosis, osteoporosis, and other conditions [22-24, 26, 27]. In our study, we found increased levels of PDE4 isoforms in skin from patients with AD. Furthermore, we also found that apremilast normalized the altered expression of several pro-inflammatory mediators such as IL-12/IL-23p40, IL-31, alarmins, and SPRR1 in IL-4- and IL-17-stimulated HEKa cells. These results are consistent with an early study that demonstrated PDE activity was increased in mononuclear leukocytes from patients with $\mathrm{AD}[21]$.

The cytokine IL-31 is related to cutaneous lymphocyteassociated antigen positive (CLA+) T cells and is considered a relevant target for treatment of pruritus [41, 42]. The ability of apremilast, a selective PDE4 inhibitor, to regulate IL-31 production in IL-4- and IL-17-stimulated keratinocytes further supports the hypothesis that normalization of PDE4/cAMP activity may be therapeutically beneficial for patients with AD.

Based on these preclinical observations, a phase II, double-blind, placebo-controlled trial evaluating apremilast efficacy, safety, and pharmacodynamics in adults with moderate to severe AD was conducted (ClinicalTrials.gov identifier NCT02087943) [43]. Patients were randomized to apremilast $30 \mathrm{mg}$ twice daily, apremilast $40 \mathrm{mg}$ twice daily, or placebo for 12 weeks and then re-randomized to doubleblind treatment with apremilast 30 or $40 \mathrm{mg}$ twice daily challenge using the Luminex assay. Data are expressed as the mean \pm standard error of the mean. $D E X$ dexamethasone, $* P<0.05$ vs. vehicle using one-way analysis of variance

through Week 24 (patients initially randomized to apremilast continued their assigned dose). Patients who received apremilast $40 \mathrm{mg}$ twice daily demonstrated significantly greater improvement from baseline on the primary endpoint, percentage change from baseline on the Eczema Area and Severity Index score at Week 12, than with placebo (mean [standard deviation $\{\mathrm{SD}\}] 31.6 \%$ [44.6] vs. $-11.0 \%$ [71.2], $P<0.04$; effect size $[95 \%$ confidence interval $\{\mathrm{CI}\}-20.6$ $[-39.7$ to -1.5$]$ ), and a trend was observed for greater improvement with apremilast $30 \mathrm{mg}$ twice daily versus placebo (mean [SD] - 26.0\% [40.1]; effect size [95\% CI] 15.0 [ -34.5 to 4.5 ], $P=$ not significant). There were no statistically significant differences in the proportion of patients who achieved static Physician's Global Assessment-Acute signs (sPGA-A) response at Week 12 with apremilast $40 \mathrm{mg}$ twice daily $(14.3 \%$ [9/63]) or apremilast $30 \mathrm{mg}$ twice daily $(3.4 \%$ [2/58]) versus placebo $(6.3 \%$ [4/64]) (effect sizes [95\% CIs]: 8.0 [ -2.3 to 18.2$]$ and -2.7 [ -10.2 to 4.8$]$, respectively). Adverse events, including cellulitis, were more frequent with apremilast $40 \mathrm{mg}$ twice daily. An independent safety monitoring committee and an external data monitoring committee recommended that the apremilast $40 \mathrm{mg}$ twice daily dose be discontinued and patients reassigned to apremilast $30 \mathrm{mg}$ twice daily [43].

Our preclinical results support previous studies and suggest that apremilast is an effective inhibitor of the Th17 
pathway in keratinocytes. In the phase II study of apremilast in patients with moderate to severe AD (NCT02087943), Th17 (IL-17A, IL-12B/IL-12/23p40) and Th17/Th22-associated markers (IL-22, S100A7/S100A8, S100A12) were significantly reduced with apremilast $40 \mathrm{mg}$ twice daily, with K16 mRNA showing the highest, most significant decreases $(P<0.05$ for all). Reductions were also observed in Th2associated cytokines (IL-13, IL-31, CCL17) in the apremilast $40 \mathrm{mg}$ twice daily and placebo groups. There were no significant reductions in tissue mRNA in patients treated with apremilast $30 \mathrm{mg}$ twice daily. IL-17 has been shown to play an important role in the pathogenesis of different $A D$ phenotypes and the regulation of the Th2 response [44, 45]. However, these pharmacological activities alone may not be sufficient for apremilast to demonstrate clinical efficacy in $\mathrm{AD}$, as efficacy was only modest with the $40 \mathrm{mg}$ twice daily dose and not statistically significant different from placebo with the $30 \mathrm{mg}$ twice daily dose. Nonetheless, given the efficacy of the topical PDE4 inhibitor crisaborole, these results demonstrate direct effects of PDE4 inhibition on skin keratinocytes and gene expression, particularly those in the Th17 pathway.

\section{Conclusion}

We have shown that all PDE4 isoforms are up-regulated in AD skin and that inhibiting PDE activity normalizes inflammatory cytokines and reduces dermatitis in mouse models. These data provide novel insights into the dysregulation of PDE4 expression in inflammatory skin from AD patients, and highlight the potential direct effects and limitations of PDE4 inhibition on keratinocyte responses within this disease context.

Acknowledgements The authors would like to acknowledge editorial support received in the preparation of this manuscript from Ruggero Galici, Ph.D., and Robert Merker, Ph.D., of Celgene Corporation, and from Karen Dougherty, Ph.D., of Peloton Advantage, LLC, an OPEN Health company, funded by Celgene Corporation.

\section{Compliance with Ethical Standards}

Conflict of interest PH. Schafer, M. Adams, and G. Horan are employees of Celgene Corporation, and have equity ownership; P.H Schafer and M. Adams hold a patent (WO2014074846 A1) for the use of apremilast in the treatment of atopic dermatitis. F. Truzzi, A. Marconi, and C. Pincelli have no conflicts or potential conflicts of interest to disclose.

Funding This research was supported by Celgene Corporation and the University of Modena and Reggio Emilia.

Ethical approval All applicable international, national, and/or institutional guidelines for the care and use of animals were followed.
Author contributions PH Schafer and $\mathrm{CP}$ conceptualized the research. PHS, MA, and GH performed and analyzed the gene expression studies in stimulated keratinocytes. FT, AM, and CP performed and interpreted the immunohistochemical analysis of the PDE4 isoforms. All of the experiments and analyses related to the two mouse models of atopic dermatitis were contracted to MD Biosciences, St Paul, MN, USA. In addition, all authors have contributed to the critical review and editing, approved this manuscript, and are accountable for the work performed.

Open Access This article is distributed under the terms of the Creative Commons Attribution-NonCommercial 4.0 International License (http://creativecommons.org/licenses/by-nc/4.0/), which permits any noncommercial use, distribution, and reproduction in any medium, provided you give appropriate credit to the original author(s) and the source, provide a link to the Creative Commons license, and indicate if changes were made.

\section{References}

1. Leung DY. New insights into atopic dermatitis: role of skin barrier and immune dysregulation. Allergol Int. 2013;62(2):151-61.

2. Bieber T. Atopic dermatitis. N Engl J Med. 2008;358(14):1483-94.

3. Morar N, Willis-Owen SA, Moffatt MF, Cookson WO. The genetics of atopic dermatitis. J Allergy Clin Immunol. 2006;118(1):2434 (quiz 5-6).

4. Thomsen SF, Ulrik CS, Kyvik KO, Skadhauge LR, Steffensen I, Backer V. Findings on the atopic triad from a Danish twin registry. Int J Tuberc Lung Dis. 2006;10(11):1268-72.

5. Kuo IH, Yoshida T, De Benedetto A, Beck LA. The cutaneous innate immune response in patients with atopic dermatitis. $\mathrm{J}$ Allergy Clin Immunol. 2013;131(2):266-78.

6. Boguniewicz M, Leung DY. Atopic dermatitis. J Allergy Clin Immunol. 2006;117(2 Suppl Mini-Primer):S475-80.

7. Johnson-Huang LM, McNutt NS, Krueger JG, Lowes MA. Cytokine-producing dendritic cells in the pathogenesis of inflammatory skin diseases. J Clin Immunol. 2009;29(3):247-56.

8. Bruijnzeel-Koomen CA, Fokkens WJ, Mudde GC, Bruijnzeel PL. Role of Langerhans cells in atopic disease. Int Arch Allergy Appl Immunol. 1989;90(Suppl 1):51-6.

9. Guttman-Yassky E, Dhingra N, Leung DY. New era of biologic therapeutics in atopic dermatitis. Expert Opin Biol Ther. 2013;13(4):549-61.

10. Guttman-Yassky E, Nograles KE, Krueger JG. Contrasting pathogenesis of atopic dermatitis and psoriasis-part II: immune cell subsets and therapeutic concepts. J Allergy Clin Immunol. 2011;127(6):1420-32.

11. Hamilton JD, Suarez-Farinas M, Dhingra N, Cardinale I, Li X, Kostic A, et al. Dupilumab improves the molecular signature in skin of patients with moderate-to-severe atopic dermatitis. J Allergy Clin Immunol. 2014;134(6):1293-300.

12. Serezani CH, Ballinger MN, Aronoff DM, Peters-Golden M. Cyclic AMP: master regulator of innate immune cell function. Am J Respir Cell Mol Biol. 2008;39(2):127-32.

13. Conti M, Beavo J. Biochemistry and physiology of cyclic nucleotide phosphodiesterases: essential components in cyclic nucleotide signaling. Annu Rev Biochem. 2007;76:481-511.

14. Houslay MD, Schafer P, Zhang KY. Keynote review: phosphodiesterase-4 as a therapeutic target. Drug Discov Today. 2005;10(22):1503-19.

15. Schett G, Sloan VS, Stevens RM, Schafer P. Apremilast: a novel PDE4 inhibitor in the treatment of autoimmune and inflammatory diseases. Ther Adv Musculoskelet Dis. 2010;2(5):271-8. 
16. Manganiello VC, Murata T, Taira M, Belfrage P, Degerman E. Diversity in cyclic nucleotide phosphodiesterase isoenzyme families. Arch Biochem Biophys. 1995;322(1):1-13.

17. Obernolte R, Ratzliff J, Baecker PA, Daniels DV, Zuppan P, Jarnagin $\mathrm{K}$, et al. Multiple splice variants of phosphodiesterase PDE4C cloned from human lung and testis. Biochim Biophys Acta. 1997;1353(3):287-97.

18. Enoksson S, Degerman E, Hagstrom-Toft E, Large V, Arner P. Various phosphodiesterase subtypes mediate the in vivo antilipolytic effect of insulin on adipose tissue and skeletal muscle in man. Diabetologia. 1998;41(5):560-8.

19. Perez-Torres S, Miro X, Palacios JM, Cortes R, Puigdomenech P, Mengod G. Phosphodiesterase type 4 isozymes expression in human brain examined by in situ hybridization histochemistry and $[3 \mathrm{H}]$ rolipram binding autoradiography. Comparison with monkey and rat brain. J Chem Neuroanatomy. 2000;20(3-4):349-74.

20. Schafer PH, Truzzi F, Parton A, Wu L, Kosek J, Zhang LH, et al. Phosphodiesterase 4 in inflammatory diseases: effects of apremilast in psoriatic blood and in dermal myofibroblasts through the PDE4/CD271 complex. Cell Signal. 2016;28(7):753-63.

21. Grewe SR, Chan SC, Hanifin JM. Elevated leukocyte cyclic AMPphosphodiesterase in atopic disease: a possible mechanism for cyclic AMP-agonist hyporesponsiveness. J Allergy Clin Immunol. 1982;70(6):452-7.

22. Videla S, Vilaseca J, Medina C, Mourelle M, Guarner F, Salas A, et al. Selective inhibition of phosphodiesterase-4 ameliorates chronic colitis and prevents intestinal fibrosis. J Pharmacol Exp Ther. 2006;316(2):940-5.

23. Keshavarzian A, Mutlu E, Guzman JP, Forsyth C, Banan A. Phosphodiesterase 4 inhibitors and inflammatory bowel disease: emerging therapies in inflammatory bowel disease. Exp Opin Invest Drugs. 2007;16(9):1489-506.

24. Press NJ, Banner KH. PDE4 inhibitors - a review of the current field. Prog Med Chem. 2009;47:37-74.

25. Schafer PH, Parton A, Capone L, Cedzik D, Brady H, Evans JF, et al. Apremilast is a selective PDE4 inhibitor with regulatory effects on innate immunity. Cell Signal. 2014;26(9):2016-29.

26. Donohue JF. Therapeutic responses in asthma and COPD. Bronchodilators. Chest. 2004;126(2):125S-37S (discussion 59S-61S).

27. Banner KH, Trevethick MA. PDE4 inhibition: a novel approach for the treatment of inflammatory bowel disease. Trends Pharmacol Sci. 2004;25(8):430-6.

28. Otezla [package insert]. Summit, NJ: Celgene Corporation; July 2019.

29. Schafer PH, Chen P, Fang L, Wang A, Chopra R. The pharmacodynamic impact of apremilast, an oral phosphodiesterase 4 inhibitor, on circulating levels of inflammatory biomarkers in patients with psoriatic arthritis: substudy results from a phase III, randomized, placebo-controlled trial (PALACE 1). J Immunol Res. 2015;2015:906349.

30. Schafer PH, Parton A, Gandhi AK, Capone L, Adams M, Wu L, et al. Apremilast, a cAMP phosphodiesterase-4 inhibitor, demonstrates anti-inflammatory activity in vitro and in a model of psoriasis. Br J Pharmacol. 2010;159(4):842-55.

31. Gottlieb AB, Matheson RT, Menter A, Leonardi CL, Day RM, Hu $\mathrm{C}$, et al. Efficacy, tolerability, and pharmacodynamics of apremilast in recalcitrant plaque psoriasis: a phase II open-label study. J Drugs Dermatol. 2013;12(8):888-97.

32. Wang X, Bao K, Wu P, Yu X, Wang C, Ji L, et al. Integrative analysis of lncRNAs, miRNAs, and mRNA-associated ceRNA network in an atopic dermatitis recurrence model. Int J Mol Sci. 2018;19(10):3263.

33. Kim J, Lee J, Shin S, Cho A, Heo Y. Molecular mechanism of atopic dermatitis induction following sensitization and challenge with 2,4-dinitrochlorobenzene in mouse skin tissue. Toxicol Res. 2018;34(1):7-12.

34. Ehinger AM, Gorr G, Hoppmann J, Telser E, Ehinger B, Kietzmann M. Effects of the phosphodiesterase 4 inhibitor RPR 73401 in a model of immunological inflammation. Eur J Pharmacol. 2000;392(1-2):93-9.

35. Rees JL, Matthews JN, Friedmann PS. Quantifying anti-inflammatory agents' potency by measurement of response to dinitrochlorobenzene challenge. J Dermatol Sci. 1992;4(1):1-5.

36. European Medicines Agency. Otezla EPAR public assessment report. London: European Medicines Agency; 2019.

37. Otezla [product monograph]. Mississauga, Ontario, Canada: Celgene Inc.; 2017.

38. Rajesh A, Wise L, Hibma M. The role of Langerhans cells in pathologies of the skin. Immunol Cell Biol. 2019;97(8):700-13.

39. Yoshida K, Kubo A, Fujita H, Yokouchi M, Ishii K, Kawasaki H, et al. Distinct behavior of human Langerhans cells and inflammatory dendritic epidermal cells at tight junctions in patients with atopic dermatitis. J Allergy Clin Immunol. 2014;134(4):856-64.

40. Didovic S, Opitz FV, Holzmann B, Forster I, Weighardt H. Requirement of MyD88 signaling in keratinocytes for Langerhans cell migration and initiation of atopic dermatitis-like symptoms in mice. Eur J Immunol. 2016;46(4):981-92.

41. Bilsborough J, Leung DY, Maurer M, Howell M, Boguniewicz M, Yao L, et al. IL-31 is associated with cutaneous lymphocyte antigen-positive skin homing $\mathrm{T}$ cells in patients with atopic dermatitis. J Allergy Clin Immunol. 2006;117(2):418-25.

42. Dillon SR, Sprecher C, Hammond A, Bilsborough J, RosenfeldFranklin M, Presnell SR, et al. Interleukin 31, a cytokine produced by activated $\mathrm{T}$ cells, induces dermatitis in mice. Nat Immunol. 2004;5(7):752-60.

43. Simpson E, Imafuku S, Poulin Y, Ungar B, Zhou L, Malik K, et al. A phase 2 randomized trial of apremilast in patients with atopic dermatitis. J Invest Dermatol. 2019;139(5):1063-72.

44. Guttman-Yassky E, Krueger JG. Atopic dermatitis and psoriasis: two different immune diseases or one spectrum? Curr Opin Immunol. 2017;48:68-73.

45. Klonowska J, Glen J, Nowicki RJ, Trzeciak M. New cytokines in the pathogenesis of atopic dermatitis-new therapeutic targets. Int J Mol Sci. 2018;19(10):E3086. 